\author{
A P HALL
}

Residence in or travel from an endemic area may be the most important clue in the diagnosis.

\section{Summary}

At least four doses of quinine followed by a single dose of mefloquine or by a single dose of sulfadoxine-pyrimethamine are two highly effective regimens for chloroquine-resistant falciparum malaria. Mefloquine alone is valuable in ambulant patients. Chloroquine-sensitive falciparum malaria can be treated with a course of chloroquine. Vivax and all other types of malaria should be treated with sequential chloroquine and primaquine. Quinine, by intravenous infusion, is the most effective drug for severe falciparum malaria. The optimum intravenous dose varies between $5 \mathrm{mg} / \mathrm{kg}$ and $10 \mathrm{mg} / \mathrm{kg}$ administered over four hours. Intravenous or oral quinine should be administered about every 12 hours and the total daily dose of quinine should rarely exceed $20 \mathrm{mg} / \mathrm{kg}$.

Intravenous fluid input should be controlled in falciparum malaria to prevent pulmonary oedema. Established renal failure is best treated by dialysis. The value of adrenocortical steroids for falciparum coma has not been established. Fresh blood transfusion may be helpful in small doses for severe anaemia and to replace clotting factors. Anticoagulants, such as heparin, should not be used in falciparum malaria.

\section{Introduction}

The two major mistakes in the management of malaria are a delay in diagnosis and excessive or inappropriate treatment.

US Army Medical Component, South East Asia Treaty Organisation, Bangkok, Thailand

A P HALL, MRCP, FACP, colonel, chief of department of medicine (now consultant physician, Hospital for Tropical Diseases, London NW1 OPE)

\section{Clinical features}

Human malaria is usually caused by one of two species, Plasmodium falciparum or $P$ vivax. $P$ malariae and $P$ ovale less commonly cause malaria, and occasionally man is infected by a monkey strain-for example, $P$ knowlesi. Apart from mosquito bite, malaria may be transmitted by blood transfusion ${ }^{1}$ or, in drug addicts, by shared syringes.

Falciparum malaria may be fatal because of the development of high parasite densities in the blood. The patient may present in coma or conscious but gravely ill. All degrees of clinical severity occur and some people are asymptomatic carriers of the parasite. Fever, chills, and headache are the commonest symptoms. In falciparum malaria, abdominal pain or jaundice without fever may suggest another diagnosis. The commonest physical findings of malaria are fever, splenomegaly, hepatomegaly, and orthostatic hypotension.

\section{Microscopic diagnosis}

If malaria is suspected a thick blood film should be stained with Giemsa or another suitable stain and examined under an oil-immersion lens. If the initial film is negative further films should be examined every few hours until the diagnosis has been established or reasonably excluded. Malaria is one of the few diseases in which the concentration of the organisms in the blood can be determined. The most accurate technique counts the parasites directly, using a measured volume of blood spread as a thick film over a measured area on the slide, and using a calibrated grid in the eye-piece. ${ }^{2}$ In the other thick-film technique the parasites are counted in relation to the number of white cells seen on the slide-for example, number of parasites per 100 or 200 white blood cells. The absolute white blood cell count is determined by a separate technique or an arbitrary figure is assumedfor example, $8000 \times 10^{9} / 1\left(8000 / \mathrm{mm}^{3}\right)$. The thick film is at least 10 times thicker than the thin film and thus it is at least 10 times easier to find parasites. The least accurate technique is to determine the proportion of red cells parasitised on the thin blood film. Species identification is more accurately determined on the thin film, however.

On the thick film $P$ falciparum usually appears as a series of thin 
blue rings with a red chromatin dot. The concentration of parasites may be high-for example, over $1000 ; 10^{9} / 1\left(1000000 / \mathrm{mm}^{3}\right)$. The presence of schizonts (mature parasites containing multiple developing forms appearing as dots) is a serious prognostic sign. If present, the sausage-shaped gametocytes of $P$ falciparum are typical. With the other malarias the parasites usually appear in various forms but the overall concentration is low (usually less than $50 \cdot 10^{9} 1\left(50000 / \mathrm{mm}^{3}\right)$ ) Amoeboid forms may predominate. Mixed infections, of course, occur-for example, $P$ falciparum with $P$ vivax.

\section{Overall management}

Patients mildly ill with malaria may be treated outside hospital, but the clinical condition may deteriorate rapidly so a period of observation is desirable. At the very least, a four-hour intravenous infusion of quinine can be given on a bed in the clinic followed by oral medication as an outpatient. Patients can be admitted for one, two, three, or more days, depending on their response to treatment. If the patients are admitted to a special malaria ward staffed with experienced nurses their management can be efficient and economical. Severe malaria may be difficult to manage and whenever possible ward rounds should be conducted by two or more doctors. Inpatient management of malaria should be co-ordinated with the treatment of the disease in clinics and follow-up examinations.

\section{CHLOROQUINE-SENSITIVE FALCIPARUM MALARIA}

The current teaching is that falciparum malaria in Africa ${ }^{3}$ and certain other areas responds to chloroquine. Nevertheless, partial resistance to chloroquine is regularly reported from these areas. There is evidence that quinine is more rapidly effective than chloroquine in patients with falciparum malaria acquired in Africa. ${ }^{4} \mathrm{Ob}$ viously a detailed prospective comparison of quinine and chloroquine with and without terminal pyrimethamine-sulfadoxine (Fansidar) for chloroquine-sensitive falciparum malaria is long overdue." There is evidence that quinine and chloroquine are antagonistic and should therefore not be used together in treating malaria. ${ }^{6}$ The routine course of chloroquine in adults is $1.5 \mathrm{~g}$, or $30 \mathrm{mg} / \mathrm{kg}$, orally given in divided doses-for example, $600 \mathrm{mg}$ initially, $300 \mathrm{mg}$ six hours later, and then $300 \mathrm{mg}$ daily for the next two days. Chloroquine (or amodiaquine) can cause death, especially when injected into children, in whom the dose should be less than in adults-for example, a total dose of $20 \mathrm{mg} / \mathrm{kg}$ rather than $30 \mathrm{mg} / \mathrm{kg}$. Intramuscular chloroquine is recommended in adults but its value should probably be re-evaluated, as should the role of chloroquine by intravenous infusion.

\section{CHLOROQUINE-RESISTANT FALCIPARUM MALARIA}

A short course of quinine (about four doses) followed by a single $1.5 \mathrm{~g}$ dose of mefloquine cured all of 35 patients with chloroquine-resistant falciparum malaria (see table I). Quinine-mefloquine is the most effective regimen yet tested.

In 1974 a short course of quinine (average 6.7 doses) followed by a single dose of Fansidar pyrimethamine $75 \mathrm{mg}$ with sulfadoxine $1.5 \mathrm{~g}$ in adults had a $96^{\circ}{ }^{\circ}$ (302 out of 314) cure-rate." In 1975 an average of 4.7 doses of quinine followed by Fansidar cured $92^{\circ}{ }^{\circ}$ (36 out of 39) of patients. ' Quinine-Fansidar is the most effective

TABLE I-Falciparum malaria in Thailand: cure rates and mean parasite counts with different regimens

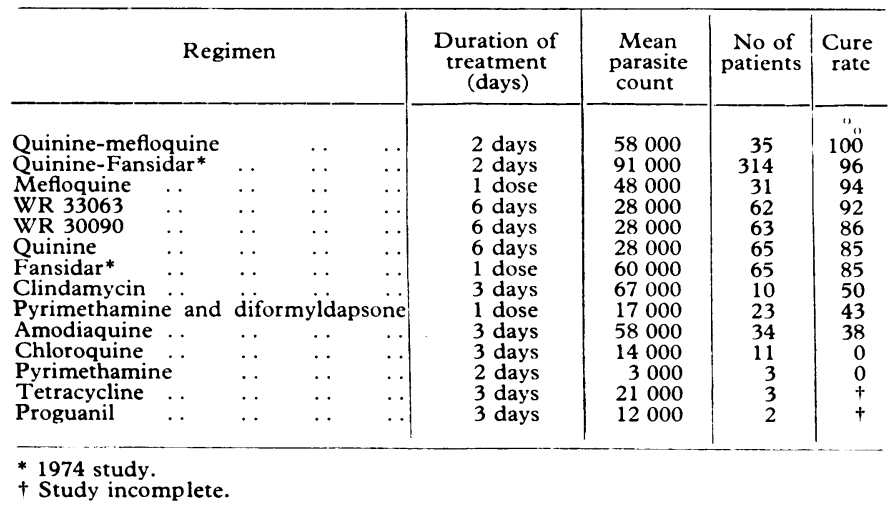

regimen using commercially available drugs. Fansidar alone is often slow-acting ${ }^{\prime}$ but is effective as a secondary drug as it helps quinine, which alone is often followed by a recrudescence, ${ }^{9}$ to eradicate the infection.

Mefloquine hydrochloride (WR 142490) is a quinoline methanol, developed by the US Army Malaria Research Program. " Given as a single dose it was highly effective in volunteers inoculated with $P$ falciparum. ${ }^{11}$ In Thailand mefloquine cleared parasitaemia and fever more quickly than Fansidar and had a higher cure-rate, " but mefloquine sometimes acted slowly and failed in the two most severe cases. Mefloquine is the most effective single-dose agent yet tested for chloroquine-resistant falciparum malaria and will be valuable in the outpatient management of the disease. Quinine-mefloquine is an outstanding regimen for patients with falciparum malaria who require admission to hospital.?

In about half the patients mefloquine alone or after quinine caused transitory side effects such as abdominal pain, dizziness, nausea, vomiting, and weakness.

Mefloquine is not yet commercially available and the manufacture of small amounts is expensive. An intravenous form is being developed. Two other compounds (WR 30090 and WR 33063) have proved of similar efficacy to oral quinine but have not been prepared in an intravenous form. ${ }^{9}$

There are many other less effective regimens available for treating falciparum malaria. ${ }^{12}$ The results with some of them are shown in table I. Of the antibiotics clindamycin given alone for three days had a cure rate of $50^{\circ}{ }_{1 .} .^{13}$ Tetracycline, given alone, is a weak antimalarial. ${ }^{13}$ Quinine for three days plus tetracycline for seven to 10 days has been recommended, ${ }^{14}$ but it is a long regimen and has not been studied in severely ill patients. Amodiaquine is a more effective 4-aminoquinoline than chloroquine for treating chloroquine-resistant falciparum malaria but was not effective enough to be recommended in Thailand. ${ }^{1 ;}$ As single-dose treatment pyrimethamine with dapsone and pyrimethamine with diformyldapsone were not very effective. ${ }^{* 16}$

The half life is important in an antimalaria! drug. The half lives in man (in hours) of various drugs used for malaria are as follows: sulfadoxine 200 , chloroquine 120 , pyrimethamine 96 , sulphametopyrazine 65 , diformyldapsone 30 , dapsone 21 , quinine 10 , tetracycline 9, trimethoprim 9, sulphamethoxazole 9, clindamycin 2, and WR 142490 (mefloquine) unknown.

\section{RECRUDESCENT INFECTIONS}

Recrudescences in falciparum malaria are quite common and are due to resurgence of the parasites in the blood. Some patients suffer multiple recrudescences. ${ }^{1 ;}$ Whenever possible the doctor should personally administer the treatment in malaria, but especially for recrudescent attacks. At least one dose of quinine should be given as an infusion in hospital if possible.

\section{Management of severe malaria and its complications}

Several complications may coexist with the malaria. For example, a patient may be admitted stuporose with anaemia, jaundice, and nosebleeds. Pulmonary oedema may then develop due to excessive intravenous fluid treatment and deep coma may be precipitated by excessive quinine treatment. Oliguric renal failure may then supervene before death. The patient may also have another disease such as typhoid, typhus, or leptospirosis.

Patient care should include as many of the following procedures as possible: continuous supervision by experienced nurses in an intensive care unit; fluid intake and output measurement; bladder catheterisation if the patient is comatose; daily weight measurement; recording of vital signs (temperature, heart rate, blood pressure, and respiratory rate) at least every four hours; and sampling of venous blood at least once daily for estimating serum quinine, bilirubin, and blood urea nitrogen concentrations, parasite count, and packed cell volume. Determination of blood gases and plasma electrolytes is indicated if respiratory or renal symptoms occur.

Detailed medical and nursing records should be made. A treatment sheet should be prepared for each patient and the date, time, and dose of each medication recorded; this reduces the chance of overdose. A precise fluid intake and output chart is essential to prevent pulmonary oedema.

Severe falciparum malaria is a medical emergency and an intravenous infusion of quinine should be begun as soon as the diagnosis has been made. The body weight is one factor in determining the dose of each drug. It is widely thought that tissue anoxia is common in the 
disease, so oxygen treatment should be considered. A hyperbaric oxygen chamber would be theoretically desirable. No controlled studies have been performed on corticosteroids, anticoagulants, dextran, or mannitol.

\section{QUININE TREATMENT}

Quinine given in intermittent intravenous infusions is the only regimen currently available ${ }^{18}$ that is effective in patients seriously ill with chloroquine-resistant falciparum malaria (table II). The half life of quinine is about 10 hours in health but is usually prolonged in falciparum malaria because of hepatic impairment. ${ }^{19}$ Therefore the required dose is inversely related to the severity of the disease. To avoid toxicity not more than $20 \mathrm{mg} / \mathrm{kg}$ should be administered daily in the early stages of the infection. In patients with severe renal or hepatic failure the optimum dose may be $10-15 \mathrm{mg} / \mathrm{kg}$ daily. The standard dose is $10 \mathrm{mg} / \mathrm{kg}$, but $5 \mathrm{mg} / \mathrm{kg}$ may be the maximum tolerated intravenous dose in severely ill patients. The optimum dosage interva is 12 hours rather than eight hours to prevent quinine toxicity. ${ }^{19} \mathrm{After}$ the initial response to treatment, $20 \mathrm{mg} / \mathrm{kg}$ usually rapidly reduces the parasitaemia to zero but $30 \mathrm{mg} / \mathrm{kg}$ is very occasionally necessary in infections showing resistance to quinine.

TABLE II-Intravenous quinine and fluid infusion in falciparum malaria: guidelines for daily dosage*

\begin{tabular}{|c|c|c|c|c|c|}
\hline $\begin{array}{l}\text { Weight of } \\
\text { patient } \\
(\mathrm{kg})\end{array}$ & $\begin{array}{l}\text { Daily } \\
\text { quinine } \\
\text { dose } \\
(\mathrm{mg})\end{array}$ & $\begin{array}{c}\text { Daily } \\
\text { volume of } \\
\text { fluid }{ }^{\dagger} \\
(\mathrm{ml})\end{array}$ & $\begin{array}{c}\text { No of } \\
\text { infusions }\end{array}$ & $\begin{array}{l}\text { Infusion } \\
\text { rate } \\
(\mathrm{ml} / \mathrm{h})\end{array}$ & $\begin{array}{c}\begin{array}{c}\text { Infusion } \\
\text { rate }\end{array} \\
\text { (drops/min } \\
(\text { approx)) }\end{array}$ \\
\hline $\begin{array}{c}5 \ldots \\
10 \ldots \\
25 \ldots \\
50 \ldots\end{array}$ & $\begin{array}{r}100 \\
200 \\
500 \\
1000\end{array}$ & $\begin{array}{r}200 \\
200 \\
500 \\
1000\end{array}$ & $\begin{array}{l}1 \\
1 \\
2 \\
2\end{array}$ & $\begin{array}{r}25 \\
50 \\
63 \\
125\end{array}$ & $\begin{array}{l}10 \\
20 \\
25 \\
50\end{array}$ \\
\hline
\end{tabular}

* Standard daily dose of quinine base is $20 \mathrm{mg} / \mathrm{kg}$. Standard ampoule contains abou $500 \mathrm{mg}$ quinine base. Recommended daily intravenous fluid intake is $20 \mathrm{ml} / \mathrm{kg}$ $(40 \mathrm{ml} / \mathrm{kg}$ in small children).

+ Standard infusion time is four hours for each infusion.

A two-hour infusion is the most effective method of administering quinine especially if the blood is free of the drug before treatment, but a longer infusion time-for example, four hours-causes less toxicity. Occasionally a quinine infusion will produce severe neurological toxicity, which may begin as twitching of the lips followed by shaking of the limbs, delirium, confusion, convulsions, and coma. If such symptoms occur the drip should be stopped. In general, if clinical deterioration occurs during an infusion treatment should be stopped when $5 \mathrm{mg}$ of the $10 \mathrm{mg} / \mathrm{kg}$ has been infused.

Nevertheless, quinine is still the most rapidly acting drug in patients severely ill with chloroquine-resistant falciparum malaria and used correctly very rarely causes serious toxicity.

\section{CEREBRAL MALARIA}

Cerebral malaria may present as coma, convulsions (common in children), stupor, confusion, aphasia, delusional states, and psychosis. $^{2021}$ Deep coma is often irreversible whereas the other forms of cerebral malaria usually respond to treatment. If asexual forms of $P$ falciparum can be detected in the blood on microscopy any cerebral signs are probably caused by the malaria. Falciparum malaria is often forgotten as a cause of coma. ${ }^{22}$ The other malarias ( $P$ vivax, etc) do not often cause coma although hemiplegia and aphasia due to $P$ vivax have been reported. ${ }^{23}$

In many patients falciparum coma is light and ephemeral and responds to a small dose of intravenous quinine. ${ }^{24}$ The usual dose of quinine is 5 to $10 \mathrm{mg} / \mathrm{kg}$ every 12 to 24 hours.

It has been claimed that intravenous corticosteroids reduce cerebra oedema $^{25}$ and are beneficial in cerebral malaria. ${ }^{2126} 27$ In other studies no effect has been apparent. ${ }^{28}{ }^{29} \mathrm{My}$ impression is that corticosteroids -for example, dexamethazone-may hasten the recovery of consciousness in the occasional case but that quinine alone is usually sufficient. A controlled trial of corticosteroids in falciparum coma is long overdue. Perhaps intravenous hydrocortisone at six-hourly intervals should be evaluated rather than dexamethazone. Dextran has also been recommended for cerebral malaria, ${ }^{21}{ }^{30}$ but a controlled study has not been performed.

\section{JAUNDICE}

The reported prevalence of jaundice in falciparum malaria varies from $1^{\circ}{ }_{0}^{31}$ to $72^{\circ}$ o in a group of fatal cases. ${ }^{32}$ The prevalence and severity of the jaundice is directly related to the density of the falciparum parasitaemia-that is more severely ill patients are more likely to be jaundiced. ${ }^{33}$ In a recent group of patients the serum bilirubin correlated negatively with the packed cell volume, which confirms that the jaundice is at least partly due to haemolysis. The serum bilirubin also correlated positively with the serum alanine aminotransferase and the serum alkaline phosphatase, which indicates that hepatic damage also contributes to the jaundice. ${ }^{33}$ Jaundice in the other malarias is probably very rare. ${ }^{33}$ Apart from jaundice, abnormality of hepatic function in falciparum malaria is common. ${ }^{34} \mathrm{Hepa}-$ tomegaly occurs in about half the cases of malaria $;^{31}$ after recovery the liver returns to its normal size within a few days.

The jaundice of falciparum malaria requires no special treatment, but drugs that are metabolised by the liver, such as quinine, should be given in reduced doses or less often. There is evidence that quinine can damage the liver, ${ }^{35}$ but reduction of the parasite density by quinine is usually associated with a rapid reduction in the serum bilirubin concentration. 33

\section{ANAEMIA}

Anaemia is common in falciparum malaria, the reported incidence varying from $20 \%$ to $45^{\circ}$ o if anaemia is defined as a packed cell volume of less than $35^{\circ} .^{36}$ Anaemia is less common in vivax malaria but few data on this subject have been published. The decrease in erythrocytes is mainly due to haemolysis, but the degree of haemolysis is greater than can be accounted for by destruction of only parasitised erythrocytes in the peripheral blood. The degree of anaemia is usually related to the severity of the infection. ${ }^{36}$ The fact that haemopoietic recovery is often slow, despite eradication of parasitaemia, may be due to the disease or the chemotherapy used-for example, there is evidence that pyrimethamine treatment may delay recovery from anaemia. ${ }^{37}$ It has been claimed that recovery from leucopenia and anaemia is more rapid in patients who receive folic or folinic acid supplements. The antimalarial effect of pyrimethamine was not impaired by the addition of folates. ${ }^{37} 38$ The anaemia of falciparum malaria improves steadily once the infection has been brought under control; blood transfusion is rarely required, 3639 and, if necessary, should be given after the parasitaemia has been greatly reduced or eliminated, because haemolysis of the transfused cells is probably less of a problem in the early convalescent period.

A positive antiglobulin (Coombs) test result is rare in falciparum malaria ${ }^{40}$ and has been described in one case of vivax malaria. ${ }^{41}$

\section{ABNORMAL BLEEDING}

Abnormal bleeding may occur in severe falciparum malaria. The presenting symptom in one of my patients was visual impairment due to retinal hemorrhages. Nosebleeds and oozing of blood about venepuncture sites are fairly common. The passage of blood in the stool (melaena) may precede death, especially in children.

The excessive bleeding is due either to decreased production of clotting factors by a damaged liver ${ }^{42}$ or to the increased intravascular consumption of clotting factors (disseminated intravascular coagulation (DIC). Early evidence for DIC was that intravenously injected plasma fibrinogen (labelled with radioactive iodine) fell precipitously in two patients with cerebral malaria, whereas in four less seriously ill patients the decrease equalled that in control subjects. ${ }^{43}$ Supporting evidence for DIC was the presence of fibrin-split products in the plasma of many patients with falciparum malaria, ${ }^{294-46}$ especially the cerebral cases, ${ }^{45}$ but other studies have been negative. ${ }^{42} 47 \mathrm{~A}$ decrease in plasma coagulation factors ${ }^{44}$ is further evidence for DIC. The euglobulin lysis time is rarely decreased in falciparum malaria, 4244 however, which suggests that the complete syndrome of DIC is rare. Also necropsies in cases of cerebral malaria have shown little evidence for thrombosis in the cerebral vessels. ${ }^{30} 32$ In one study of 53 patients no one had the classical syndrome of DIC with bleeding. Sporadic abnormalities in coagulation were attributed to hypersplenism, drug toxicity, and liver disease. ${ }^{42}$ In another study mildly increased intravascular coagulation was detected in $33 \%$ of cases (8 out of 24) and was closely associated with a heavy parasitaemia of $P$ falciparum. ${ }^{18}$ Thrombocytopenia without DIC is common in falciparum $^{49}$ and vivax ${ }^{50}$ malaria and is probably due to splenic pooling of platelets. ${ }^{51}$ 
Complement (C3) reduction in falciparum malaria correlates with the degree of anaemia, thrombocytopenia, and DIC. Complement activation may contribute to DIC and promote release of vascular permeability factor-for example kinins. ${ }^{52}$

Heparin has been recommended for the DIC of malaria ${ }^{44}$ 5:3 54 but has caused haemorrhages that may have contributed to death in some patients. ${ }^{14: 117}$ Heparin had an antimalarial effect in monkeys in one study, ${ }^{5.5}$ but not in another, in which no effect on survival was noted.".t Therapeutic defibrination with ancrod (Arvin) benefited neither patients with cerebral malaria ${ }^{29}$ nor monkeys infected with $P$ knowlesi. ${ }^{5}$. Indeed, heparin has been implicated as the cause of DIC in two patients with pulmonary emboli. ${ }^{5.8}$ Reid has concluded that heparin should not be used in malaria. ${ }^{99}$

Transfusion of fresh blood or fresh frozen plasma will partly replace clotting factors. If only one unit of blood is infused daily haematological improvement may occur without the risk of fluid overload.

\section{BLACKWATER FEVER}

Blackwater fever refers to the passage of haemoglobin in the urine secondary to rapid or severe lysis of erythrocytes and is not always associated with impaired renal function. ${ }^{60}$ Blackwater fever is usually caused by the malaria and less commonly by quinine treatment, which often produces an improvement in the condition. Glucose-6phosphate dehydrogenase (G6PD) deficiency is probably not a relevant factor in the blackwater fever associated with acute falciparum malaria. ${ }^{61}$ There is no specific proof for the claim that adrenocorticosteroids are useful in the management of blackwater fever. ${ }^{6: 2}$

\section{RENAL DISEASE}

Acute renal insufficiency (ARI) is a rare complication of falciparum malaria. Anuria or oliguria (urine output less than $400 \mathrm{ml}$ daily) may occur. Blackwater fever (sometimes caused by incompatible blood transfusion) is sometimes associated with the renal failure. Vomiting and lack of fluid input with resultant dehydration probably contributes to ARI in some patients. Prompt use of modest amounts of intravenous fluids in severely ill patients on admission probably prevents ARI in such cases.

If oliguria occurs the osmotic diuretic mannitol has been recommended in an attempt to restore urinary output. ${ }^{62}$ Peritoneal dialysis has been effective in the management of acute renal failure in falciparum malaria. ${ }^{186: 3-65}$ Haemodialysis has also been used. ${ }^{18} 611^{66}$

Nephrotic syndrome due to $P$ malariae is common in Africa ${ }^{i ;-69}$ and is associated with the deposition of soluble immune complexes in the glomerular basement membrane. ${ }^{i}$ "The nephrotic syndrome 9 il is rare in falciparum malaria, but immune complexes have been detected on the glomerular basement membrane of patients with varying degrees of urinary abnormality. ${ }^{i 2}$

\section{PULMONARY OEDEMA}

There is statistical evidence that pulmonary oedema in falciparum malaria is often caused by excessive fluid therapy. ${ }^{73}$ Other authors have indicated that fluid overload may cause pulmonary oedema in falciparum malaria. ${ }^{74}{ }^{75}$ Most reported cases of pulmonary oedema have been associated with intravenous fluid treatment and a positive fluid balance. ${ }^{53}$ it it Excessive oral fluids can probably also precipitate pulmonary oedema.

Dehydration is not common in falciparum malaria. Indeed, the converse is usually true since there is evidence of an increased plasma volume $^{77} 78$ and an increase in tissue catabolism and fluid production in the disease. ${ }^{79}$ Hyponatraemia is also common. ${ }^{74}{ }^{79}$ These findings indicate that small volumes of intravenous saline are a suitable vehicle for quinine treatment in severely ill patients. In adults daily intake should not exceed $1500 \mathrm{ml}$ and in small adults $1000 \mathrm{ml}$ is often sufficient. If pulmonary oedema occurs a diuretic is logical treatmentfor example, intravenous frusemide can be injected slowly.

A rapidly fatal pulmonary complication has been described in severe infections. The patient develops acute dyspnoea, but evidence of gross fluid overload-for example, extensive rales-is not present. The exact pathology is not known but hyaline membrane may be a factor. This dramatic complication might be called "Acute Pulmonary Insufficiency." It does not respond to treatment. ${ }^{80}$

\section{SPLENIC RUPTURE AND SPLENOMEGALY}

Rupture of the spleen is often not diagnosed before death, especially in patients with malaria. ${ }^{\text {} 1 ~}$ Spontaneous splenic rupture occurred in three out of $422\left(0 \cdot 7^{\prime \prime}{ }_{11}\right)$ cases of vivax malaria induced in volunteers. ${ }^{{ }^{*} 2}$ Splenic rupture seems to be mostly associated with the rapid enlargement of a soft spleen in primary attacks. Defective haemostasis may be another factor in splenic rupture which may be related to the thrombocytpoenia or to defects in coagulation. ${ }^{\mathrm{K}^{2}}$ Splenic rupture may result in lower quadrant pain due to pooling of blood. A plain abdominal film may show evidence of intraperitoneal fluid, peritoneal lavage may reveal haemorrhage, and splenic arteriography may indicate a subcapsular haemorrhage. Immediate splenectomy is the treatment. ${ }^{82}$

The tropical splenomegaly syndrome, described in Africa, comprises massive splenomegaly without obvious cause except malarial parasitaemia in some patients. Antimalarial therapy is usually associated with a reduction in spleen size. ${ }^{8,3}$

\section{Drug toxicity}

Most treatment for malaria can cause death or, at least, serious toxicity. The following are some examples. Blood transfusion, if incompatible, may cause anuric renal failure. Because of circulating haemolysins, even compatible transfused red cells may be rapidly haemolysed, with resulting blackwater fever (massive haemoglobinuria). Chloroquine, especially by injection, may cause convulsions ${ }^{* 4}$ and even death. ${ }^{* 5}$ Dextran may cause anaphylaxis, renal failure, hypervolaemia, and a bleeding diathesis. ${ }^{* 6}$ Frusemide (Lasix) may cause sudden death when injected intravenously. Heparin may cause fatal haemorrhage. Peritoneal dialysis may result in peritonitis. The combination of pyrimethamine with sulfadoxine may cause severe urticarial rashes. Quinine may cause abortion, coma, convulsions, severe haemolysis, and death. Used judiciously, however, several of these modes of treatment have an important role in the disease.

\section{Vivax malaria}

If the microscopic diagnosis is unclear then the patient should be treated for falciparum malaria. Patients with vivax malaria rarely develop complications even if they have a high fever. The usually benign malarias ( $P$ vivax, $P$ malariae, and $P$ ovale) may all be treated in the same manner with chloroquine and primaquine, as can any unusual strains such as $P$ knowlesi transmitted by the mosquito from a monkey reservoir. Chloroquine is always effective in treating the clinical attack but primaquine is also needed except in blood-induced infections to eradicate the infection from the liver and thus prevent relapses. In adults chloroquine is administered as a 1.5 -g course over three days and is followed by primaquine $15 \mathrm{mg}$ daily for 14 days. ${ }^{87}$ Smaller doses are given to children.

\section{Malaria in children}

Malaria in children has been the subject of several articles. ${ }^{\times x-90}$ The general management is similar to that in adults. Chloroquine by intramuscular injection is dangerous, especially when the dose exceeds $5 \mathrm{mg} / \mathrm{kg}$. It is safer to give chloroquine as two intramuscular injections of $2.5 \mathrm{mg} / \mathrm{kg}$ separated by an interval of 6 to 12 hours. ${ }^{90}$

An alternative regimen is a slow intravenous infusion of quinine in a dose of $5-10 \mathrm{mg} / \mathrm{kg}$ at a concentration of $0.5-1.0 \mathrm{~g} / 1$ infused over four hours. Depending on the clinical and parasitaemic response this dose can be repeated about every 12 hours. The first dose can be greater in children who are older or not desperately ill. Very sick children seem to die readily from the disease or drug toxicity. Whenever possible the intravenous infusion should be administered through a $100-\mathrm{ml}$ metering chamber to avoid fluid or drug overload.

Convulsions should be treated with parenteral diazepam or paraldehyde. When the child is conscious and clinically improved the treatment should be given orally (chloroquine in Africa, etc, and quinine in chloroquine-resistant areas). For example, in a child weighing $14 \mathrm{~kg}$ half a $270-\mathrm{mg}$ quinine tablet crushed in water every 12 hours in a spoon results in a dose of $20 \mathrm{mg} \mathrm{kg}^{-1} \mathrm{day}^{-1}$. A small dose of pyrimethamine-sulfadoxine can complete the course of treatment-for example, $12.5 \mathrm{mg}$ pyrimethamine with $125 \mathrm{mg}$ sulfadoxine. 


\section{Prevention of malaria}

Prevention will be discussed briefly. Contact with mosquitoes must be avoided. In areas where malaria is endemic its incidence can be reduced by using netting around beds, insecticide spray, insect repellent, and wire mesh across windows.

The choice of drugs for the prevention (chemoprophylaxis) of malaria depends on the resistance patterns. In areas where $P$ falciparum is not resistant to chloroquine this is the most widely used drug for prophylaxis. In adults the standard dose is $300 \mathrm{mg}$ chloroquine weekly. Another 4-aminoquinoline, amodiaquine (400 $\mathrm{mg}$ weekly), is effective. Proguanil (100$200 \mathrm{mg}$ daily) or pyrimethamine (25-50 mg weekly), which are dihydrofolate acid reductase (DHFA) inhibitors, may also be used, especially if pyrimethamine resistance has not been shown in the area.

The chemoprophylaxis of chloroquine-resistant falciparum malaria is controversial. ${ }^{91}$ 9.2 Weekly chloroquine-primaquine plus daily Dapsone is still recommended, ${ }^{91}$ but this regimen was not very successful among US troops in Vietnam because many developed falciparum or vivax malaria. A relevant factor, however, may have been that the troops did not always ingest the tablets. The combination of weekly and daily medication is obviously inconvenient. Primaquine, which is administered to prevent $P$ vivax developing in the liver, causes diarrhoea and other side effects, including haemolysis, ${ }^{93}$ in some people with a deficiency of G6PD. Dapsone has been implicated in agranulocytosis. ${ }^{94}$ The use of chloroquine for chloroquine-resistant organisms is not logical ${ }^{9:}$ and there is no evidence for synergism between chloroquine, primaquine, and dapsone against $P$ falciparum.

Finally, in Vietnamese soldiers monthly Fansidar was much more effective than weekly chloroquine-primaquine plus daily dapsone for the chemosuppression of falciparum malaria. ${ }^{9 ;}$

The combination of pyrimethamine (half life about 96 hours) and sulfadoxine (half life about 200 hours), marketed as Fansidar, has been highly successful in preventing falciparum malaria when administered every week, ${ }^{96}$ every two weeks, ${ }^{97} 98$ or every four weeks. ${ }^{9100}$ The arguments against sulphone or sulphonamide prophylaxis are that drug resistance may be produced (this is true of any regimen) and that widespread prophylactic use may induce resistance in many bacterial species, especially among the pathogens responsible for periodic epidemics of cerebrospinal meningitis in Africa. But Fansidar is the most effective regimen currently available for the prevention of chloroquine-resistant falciparum malaria; it is more effective than pyrimethamine with diformyldapsone. ${ }^{9 \times}$

Weekly mefloquine was highly effective for the chemosuppression of malaria in volunteers, ${ }^{101}$ and further studies are planned.

This paper is contribution No 1382 to the US Army Research Program on Malaria.

\section{References}

1 Bruce-Chwatt, L J, Bulletin of the World Health Organization, 1974, 50,

337.
2 Earle, W C, and Perez, M, Journal of Laboratory and Clinical Medicine, $1932,17,1124$.

${ }^{3}$ Bruce-Chwatt, L J, Transactions of the Royal Society of Tropical Medicine and Hygiene, 1970, 64, 776.

${ }^{4}$ Ansdell, V E, et al, British Medical Fournal, 1974, 2, 206.

${ }^{5}$ Hall, A P, et al, British Medical fournal, 1975, 2, 15.

${ }^{6}$ Hall, A P, Transactions of the Royal Society of Tropical Medicine and Hygiene, 1973, 67, 425.

' Hall, A P, et al, submitted for publication

${ }^{8}$ Doberstyn, E B, et al, American fournal of Tropical Medicine and Hygiene, in press.

${ }^{9}$ Hall, A P, et al, Transactions of the Royal Society of Tropical Medicine and Hygiene, 1975, 69, 342.

1" Canfield, C J, and Rozman, R S, Bullet in of the World Health Organisation, 1974, 50, 203.

11 Trenholme, G M, et al, Science, 1975, 190, 792.

12 World Health Organization, Chemotherapy of Malaria and Resistance to Antimalarials, Technical Report Series No 529. Geneva, WHO, 1973.

${ }^{13}$ Hall, A P, et al, British Medical fournal, 1975, 2, 12.
14 Colwell, E J, and Hickman, R L, Annals of Tropical Medicine and Parasitology, 1973, 67, 125.

${ }^{15}$ Hall, A P, et al, American fournal of Tropical Medicine and Hygiene, 1975, 24,575 .

${ }^{16}$ Segal, H E, et al, Transactions of the Royal Society of Tropical Medicine and Hyiene, 1975, 69, 139.

1; Hall, A P, American fournal of Tropical Medicine and Hygiene, 1973, 22, 296.

${ }^{1 *}$ Stone, W J, Hanchett, J E, and Knepshield, J H, Archives of Internal Medicine, 1972, 129, 618.

19 Hall, A P, et al, submitted for publication.

20 Chipman, M, Cadigan, F C, and Benjapongse, W, Tropical and Geographical Medicine, 1967, 19, 8.

${ }^{21}$ Daroff, R B, et al, fournal of the American Medical Association, 1967, 202, 679

22 Cowan, G O, New England Fournal of Medicine, 1974, 291, 1257.

${ }_{23}^{3}$ Hill, G J, et al, Archives of Internal Medicine, 1963, 112, 863.

${ }^{24}$ Hall, A P, Karnchanachetanee, C, and Sonkom, P, submitted for publication.

${ }^{25}$ Long, D M, Hartmann, J F and French, L A, Neurology, 1966, 16, 521.

${ }^{26}$ Woodruff, A W, and Dickinson, C J, British Medical fournal, 1968, 3, 31.

27 Oriscello, R G, British Medical fournal, 1968, 3, 617.

${ }^{2 \times}$ Smith, D H, and Harper, P S, British Medical fournal, 1968, 3, 618.

29 Reid, H A, and Nkrumah, F K, Lancet, 1972, 1, 218.

30 Smitskamp, H, and Wolthuis, F H, British Medical fournal, 1971, 1, 714

31 Kern, R A, and Norris, R F, United States Naval Medical Bulletin, 1944, 43, 847 .

32. Maegraith, B G, Pathological Processes in Malaria and Blackwater Fever. Springfield, Illinois, Thomas, 1948.

${ }^{33} \mathrm{Hall}$, A P, et al, submitted for publication.

${ }^{34}$ Deller, J J, et al, Military Medicine, 1967, 132, 614.

${ }^{35}$ Hall, A P, et al, Clinical Pharmacology and Therapeutics, 1973, 14, 580.

${ }^{36}$ Hall, A P, Doberstyn, E B, and Sonkom, P, submitted for publication

37 Canfield, C J, Keller, H I, and Cirksena, W J, Military Meidicine, 1971, 136,354 .

38 Tong, M J, et al, fournal of the American Medical Association, 1970, 214, 2330.

${ }^{39}$ Blount, R E, Annals of Internal Medicine, 1969, 70, 142.

4" Adner, M M, Alstatt, L B, and Conrad, M E, Annals of Internal Medicine, $1968,68,33$.

${ }^{4}$ Barrett-Connor, E, American fournal of Tropical Medicine and Hygiene, $1967,16,699$

12 Butler, T, et al, American fournal of Medical Science, 1973, 265, 63.

${ }^{43}$ Devakul, K, Harinasuta, T, and Reid, H A, Lancet, 1966, 2, 886.

44 Dennis, L H, et al, Blood, 1967, 29, 713.

45 Jaroonvesama, N, Lancet, 1972, 1, 221.

${ }_{46}$ Paar, D, et al, British Medical fournal, 1970, 4, 805.

4 - Borochovitz, D, Crosley, A L, and Metz, J, British Medical Fournal, 1970, 2, 710 .

4* Petchclai, B, Prasongsom, S, and Benjapongs, W, Lancet, 1975, 1, 36.

49 Beale, P J, Cormack, J D, and Oldrey, T B N, Britısh Medical fournal, $1972,1,345$

50 Hill, G J, Knight, V, and Jeffrey, G M, Lancet, 1964, 1, 240.

51 Skudowitz, R B, et al, British Medical fournal, 1973, 2, 515.

52. Srichaikul, T, et al, Lancet, 1975, 1, 770.

${ }^{53}$ Punyagupta, S, Srichaikul, T, and Akarawong, K, fournal of the Medical Association of Thailand, 1972, 55, 121.

${ }^{54}$ Punyagupta, S, et al, American fournal of Tropical Medicine and Hygiene, $1974,23,551$.

55 Dennis, L H, and Conrad, M E, Lancet, 1968, 1, 769.

${ }^{56}$ Howard, W A, and Collins, W E, Lancet, 1972, 2, 738

57 Reid, H A, and Sucharit, P, Lancet, 1972, 2, 1110.

${ }^{58}$ Klein, H G, and Bell, W R, Annals of Internal Medicine, 1974, 80, 477.

59 Reid, H A, Lancet, 1975, 1, 167.

60 Canfield, C J, Bullet in of the New York Academy of Medicine, 1969, 45, 1043.

${ }^{61}$ Dukes, D C, Sealey, B J, and Forbes, J I, American fournal of Medicine, $1968,45,899$.

62 Sheehy, T W, Annals of Internal Medicine, 1967, 66, 807.

${ }^{63}$ Reid, H A, Goldsmith, H J, and Wright, F K, Lancet, 1967, 2, 436.

${ }^{64}$ Donadio, J V, Whelton, A, and Kazyak, L, Lancet, 1968, 1, 375.

${ }^{65}$ Canfield, C J, et al, Archives of Internal Medicine, 1968, 122, 199.

${ }_{66}$ Jackson, R C, and Woodruff, A W, British Medical fournal, 1962, 1, 1367.

67 Gilles, H M, and Hendrickse, R G, British Medical fournal, 1963, 2, 27.

${ }^{68}$ Kibukamusoke, J W, Hutt, M S R, and Wilks, N E, Quarterly fournal of Medicine, 1967, 36, 393.

69 Hendrickse, R G, et al, Lancet, 1972, 1, 1143.

70 Ward, P A, and Kibukamusoke, J W, Lancet, 1969, 1, 283.

${ }^{7}$ Berger, M, Birch, L M, and Conte, N F, Annals of Internal Medicine, 1967, 67, 1163.

${ }^{72}$ Bhamarapravati, N, et al, Archives of Pathology, 1973, 96, 289.

${ }^{73}$ Hall, A P, Charoendhum, D, and Sonkom, P, submitted for publication.

${ }^{74}$ Miller, L H, et al, Annals of Tropical Medicine and Parasitology, 1967, 61, 265.

75 Sitprija, V, et al, Lancet, 1967, 1, 185.

${ }^{76}$ Brooks, M H, et al, New England fournal of Medicine, 1968, 279, 732.

7 Feldman, H A, and Murphy, F D, fournal of Clinical Investigation, 1945, 24, 780 .

${ }^{78}$ Malloy, J P, Brooks, M H, and Barry, K G, American fournal of Medicine, $1967,43,745$. 
79 Brooks, $\mathrm{M} \mathrm{H}$, et al, American fournal of Medicine, 1967, 43, 735.

80 Deaton, J G, American Fournal of Tropical Medicine and Hygiene, 1970, $19,196$.

${ }^{81}$ Covell, G, Tropical Diseases Bulletin, 1955, 52, 705.

82 Howard, W A, et al, Military Medicine, 1973, 138, 32.

${ }^{83}$ Stuiver, P C, et al, British Medical fournal, 1971, 1, 426.

${ }_{84}$ Torrey, E F, fournal of the American Medical Association, 1968, 204, 867.

85 Geddes, T G, British Medical fournal, 1970, 3, 711.

${ }^{86}$ Data, J L, and Nies, A S, Annals of Internal Medicine, 1974, 81, 500.

87 Covell, G, et al, Chemotherapy of Malaria. Geneva, WHO, 1955.

88 Gilles, H M, British Medical fournal, 1966, 2, 1375.

${ }^{89}$ Hendrickse, R G, et al, Annals of Tropical Medicine and Parasitology, $1971,65,1$.

90 Ransome-Kuti, O, Advances in Pediatrics, 1972, 19, 319.

91 Barrett-Connor, E, Annals of Internal Medicine, 1974, 81, 219.

92 Pearlman, E J, and Hall, A P, Annals of Internal Medicine, 1975, 82, 590.
93 Hockwald, R S, et al, fournal of the American Medical Association, 1952, $149,1568$.

94 Ognibene, A J, Annals of Internal Medicine, 1970, 72, 521.

95 Thanh, P H, Huan, D H, and Tinh, T V, fournal of Military Medicine in Vietnam, 1971, 40, 37.

96 Lucas, A O, ot al, Transactions of the Royal Society of Tropical Medicine and Hygiene, 1969, 63, 216.

97 Laing, A B G, Bulletin of the World Health Organisation, 1970, 43, 513.

${ }_{98}$ Pearlman, E J, et al, submitted for publication.

99 O'Holohan, D R, and Hugoe-Matthews, J, Southeast Asian fournal of Tropical Medicine and Public Health, 1971, 2, 164.

${ }^{100}$ Lewis, A N, and Ponnampalam, J T, Annals of Tropical Medicine and Parasitology, 1975, 69, 1 .

${ }^{101}$ Rieckmann, $\mathrm{K} \mathrm{H}$, et al, Bulletin of the World Health Organisation, 1974, $51,375$.

\title{
Specialist registration: a critical look at the proposals of the Merrison Report
}

\author{
$M$ D VICKERS
}

British Medical fournal, 1976, 1, 328-331

\begin{abstract}
Summary
In the general euphoria over the many views in the Merrison Report that the profession welcomed too little attention has been paid to what has been said about specialist registration. The report contains several basic confusions and a serious misunderstanding of the nature of specialist medical training and practice. It makes several cardinal errors in thinking that some notorious problems related to NHS staffing are also related to a lack of an effective specialist register, and it shows how the creation of such a register would largely destroy the authority of the colleges and faculties. Nowhere in the report is there any convincing argument to show that specialist registration would confer advantages sufficient to outweigh the disadvantages. To let specialist registration in the UK slip in on the irrelevant coat tails of EEC requirements would be a grave dereliction of the long-term interests of medical practice and patient care. The General Medical Council is holding a conference in which this topic is to be discussed on 24 February 1976 and it is still not too late for the profession to think again on this topic.
\end{abstract}

\section{Introduction}

Although professional concern over the introduction of the annual retention fee was a major stimulus to the inception of the Merrison inquiry, ${ }^{1}$ anxieties about the General Medical Council's role in specialist registration were not unknown even before that. Indeed, a determination to keep the control of specialist education in the hands of relevant professional bodies was a potent stimulus to the setting up of the Joint Committees for Higher Professional Training.

\section{Dudley Road Hospital, Birmingham B18 7 QH}

$M$ D VICKERS, MB, FFA, RCS, consultant anaesthetist and honorary secretary of the Association of Anaesthetists of Great Britain and Ireland
Careful study of the Merrison Report shows that (a) the committee has muddled the meaning of "specialist" with that of "consultant," and has tried to equate specialist registration to accreditation and the completion of training; $(b)$ the members of the committee have a very imperfect idea of the nature of specialist and consultant training; (c) some notorious NHS problems are assumed to flow from the lack of specialist registration when these are clearly unrelated problems; $(d)$ the committee assumes that co-ordination between other phases of medical education and specialist training is desirable and that specialist registration would achieve it; $(e)$ having outlined how their proposals would emasculate the influence of the Royal Colleges and Faculties, they show how a body like their proposed GMC would probably misuse its power and do a great deal of harm to the profession; $(f)$ the benefits that they suggest would offset all this seem, on examination, to be illusory and illfounded.

I have thus come to a conclusion contrary not only to that of the Merrison Committee but also to that of the editorial in the British Medical fournal that commended it. ${ }^{2}$ It is difficult to believe that the author of that editorial could have been in sympathy with the BMA's evidence on this topic: "If specialist registration is eventually introduced, the standards of training, examination, and accreditation should remain the responsibility of the royal colleges' specialist faculties and specialist associations . ..."' (my italics).

The Merrison proposals are likely to lead to rather different results as may be shown from the following extracts from the report (all italics are mine unless otherwise stated).

\section{Muddles: accreditation and specialist registration}

"We believe there to be three generally recognised and recognisable stages in the development of clinical responsibility: namely practice under supervision; independent practice; and practice carrying ultimate responsibility for the care of the patient, that is, at a high specialist level. These stages correspond broadly to the three stages of registration we propose: restrictive registration, general registration, and indicative specialist registration." (Para 124.)

Comment-This is the most important paragraph on this topic. Clearly, principals in general practice (eligible for the hospital 